\title{
Changes in the surface morphology of platinum electrodes produced by the application of periodic potential treatments in alkaline solution
}

\author{
A. Visintin, W.E. Triaca and A.J. Arvia \\ Instituto de Investigaciones Fisicoquimicas Teóricas y Aplicadas (INIFTA), Facultad de Ciencias Exactas, \\ Universidad Nacional de La Plata, Casilla de Correo 16, Sucursal 4, 1900 La Plata (Argentina)
}

(Received 13 June 1989; in revised form 28 November 1989)

\begin{abstract}
The development of preferentially oriented crystalline surfaces of $\mathrm{Pt}$ with rough topographies in alkaline solution, produced by the application of periodic square wave potential treatments, is described. The influence of the different electrical variables is studied systematically and the characteristics of the different growth modes are followed through voltammetry in the $\mathrm{H}$-atom electrosorption potential range and SEM micrographs. These effects are explained in terms of a strong $\mathrm{OH}^{-}$ion-metal surface interaction which favours the formation of hydrous Pt oxide layers. The electroreduction of the latter yields $\mathrm{Pt}$ overlayers with distinguishable growth modes and preferred crystalline orientations.
\end{abstract}

\section{INTRODUCTION}

It is already well established that the surface morphology of Pt electrodes can be modified substantially by means of periodic perturbing potential treatments [1-3]. In acid electrolytes single stage treatments can, under certain conditions, produce a definite type of preferred crystalline orientation (pco) at the Pt surface [4-6]. For other conditions, treatments comprising two successive stages, namely, a first one where a hydrous metal oxide layer is accumulated on the electrode surface through a periodic potential treatment, and a second one involving the electroreduction of the hydrous Pt oxide layer, can furnish both pco and surface roughness development [7]. In this case, the roughness geometry is considerably dependent upon the operating conditions selected for the electroreduction of the hydrous $\mathrm{Pt}$ oxide layer [7-9]. However, procedures involving both a single stage and succesive stages were developed by using exclusively acid electrolytes and focussing the attention on those parameters defining the electrical perturbation, despite the fact that the solution composition, as established before [10], is also an additional variable which deserves 
further investigation. The present paper is devoted to a study of the changes in the surface morphology of $\mathrm{Pt}$ electrodes, including both the development of pco and the growth modes of rough Pt overlayers, caused by periodic potential treatment in alkaline solutions. On the basis of the reaction mechanism already advanced for the development of pco and roughness of $\mathrm{Pt}$ in acids [7,9], one can predict that the treatment in alkaline solution operates exclusively throughout the two successive stages referred to above. Furthermore, the possibility of producing changes in the $\mathbf{P t}$ surface morphology in base solution also becomes relevant in the following two respects. Firstly, the high concentration of $\mathrm{OH}^{-}$ions and the relatively strong interaction of the $\mathrm{OH}^{-}$ions with the Pt surface offer the possibility of circumventing the possible interference of traces of active surface impurities in the development of these processes. Secondly, as in base solution the overlapping of the $\mathrm{H}$-adatom and $\mathrm{OH}$-adsorbate potential ranges is greater than in acid solution [11], the influence of $\mathrm{H}$-adatoms in the morphology changes of $\mathrm{Pt}$ in alkaline solutions should become more remarkable than in acids.

The present work describes for the first time the changes in surface morphology of $\mathrm{Pt}$ in alkaline solutions promoted by a square wave perturbing potential applied over a wide range of potential windows. The development of pco, and the growth of $\mathrm{Pt}$ overlayers through the potentiostatic electroreduction of hydrous Pt oxide layers, are reported.

\section{EXPERIMENTAL}

The Pt working electrodes are microspheres grown at the tip of a Pt wire by melting one extreme of it in an oxygen + gas torch flame [12]. The geometric areas of the resulting polyfacetted $\mathrm{Pt}$ microspheres were comprised in the $0.01-0.04 \mathrm{~cm}^{2}$ range. The counter electrode was a large Pt plate of about $20 \mathrm{~cm}^{2}$ geometric area placed into a glass compartment connected directly to the rest of the cell to minimize the ohmic drop. The potential of the working electrode was measured against a reversible hydrogen electrode in the same electrolyte solution (HESS). The electrolyte solution was $1 \mathrm{M} \mathrm{NaOH}$ prepared from triply distilled water and Merck chemicals (p.a. quality). The electrode arrangement in the cell was optimized to obtain the lowest ohmic drop and the best primary potential distribution compatible with the experiments. The electronic setup for the square wave potential treatments and the conventional voltammetry measurements was the same as used in previous works $[7,13]$. Runs were made at $25^{\circ} \mathrm{C}$.

Two types of experiments were performed comprising different combinations of perturbing potentials.

(i) Experiments of type $I$ involved the following sequence of operations. Firstly, a repetitive triangular potential scan at $0.1 \mathrm{~V} / \mathrm{s}$, between 0.05 and $1.50 \mathrm{~V}$, was applied to the system to achieve a reproducible and stable voltammogram. The latter was used as reference. Then, a time-symmetric repetitive square wave potential (RSWP) treatment was applied to the working electrode in the same solution during a certain time $(t)$ between lower $\left(E_{1}\right)$ and upper $\left(E_{\mathrm{u}}\right)$ potential limits at a frequency $f$. For 
this purpose the following parameters were selected: $-0.1 \mathrm{~V} \leqslant E_{1} \leqslant 0.1 \mathrm{~V} ; 0.5$ $\mathrm{V} \leqslant E_{\mathrm{u}} \leqslant 2.6 \mathrm{~V} ; 0.1 \mathrm{kHz} \leqslant f \leqslant 6 \mathrm{kHz}$. Finally, another voltammogram was run as indicated above either in the $0.05-0.60 \mathrm{~V}$ range or in $0.05-1.50 \mathrm{~V}$ range, to follow the changes produced by the electrochemical treatment as compared to the reference. SEM micrographs of the Pt electrode surface resulting after the electrochemical treatment were obtained ex-situ in the conventional way.

(ii) Experiments of type $I I$ were initiated by running conventional voltammetry to obtain the reference current-potential profile as indicated for type I experiments. Later, a thick hydrous $\mathrm{Pt}$ oxide layer was accumulated onto the electrode surface by applying a symmetric RSWP with $E_{\mathrm{u}}=2.3 \mathrm{~V}, E_{1}=0 \mathrm{~V}, f=0.62 \mathrm{kHz}$ and $t=3$ min. Finally, the oxide layer was electroreduced under a constant potential step set
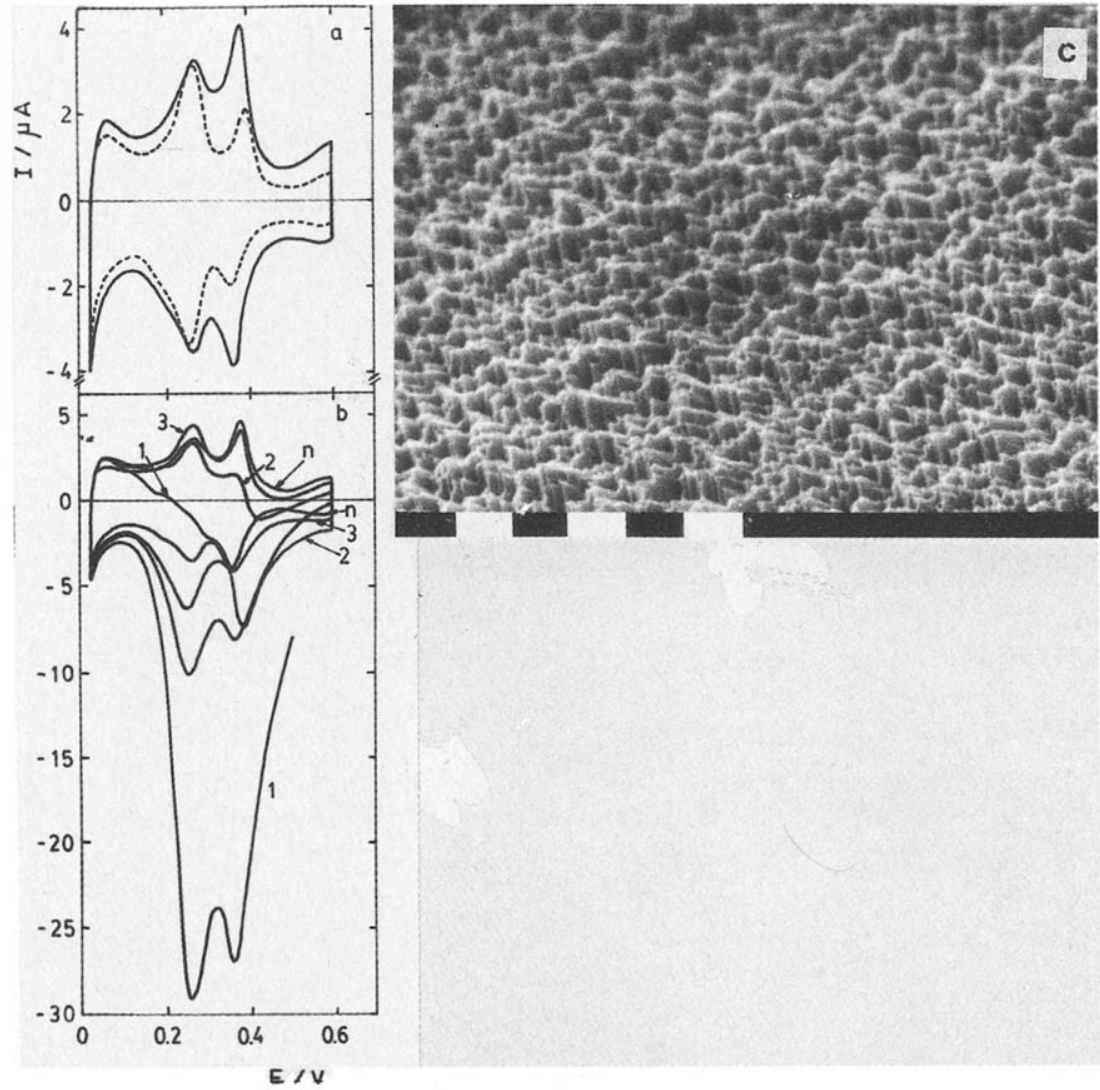

Fig. 1. Voltammograms run at $0.1 \mathrm{~V} / \mathrm{s}$ in $1 \mathrm{M} \mathrm{NaOH}, 25^{\circ} \mathrm{C}$, and SEM micrographs after $10 \mathrm{~min}$ RSWP treatment ( $E_{\mathrm{u}}=1.9 \mathrm{~V}, E_{\mathrm{l}}=0 \mathrm{~V}, f=0.62 \mathrm{kHz}$ ). (a) (- $(-)$ Stabilized voltammogram run between 0.05 and $0.60 \mathrm{~V} ;(+\ldots$.$) untreated polyfacetted Pt microsphere. (b) Transition from the first negative$ potential scan to the stabilized voltanmogram $(n=10$ th cycle). (c) SEM micrograph of the treated surface, scale: $1 \mu \mathrm{m}$. 

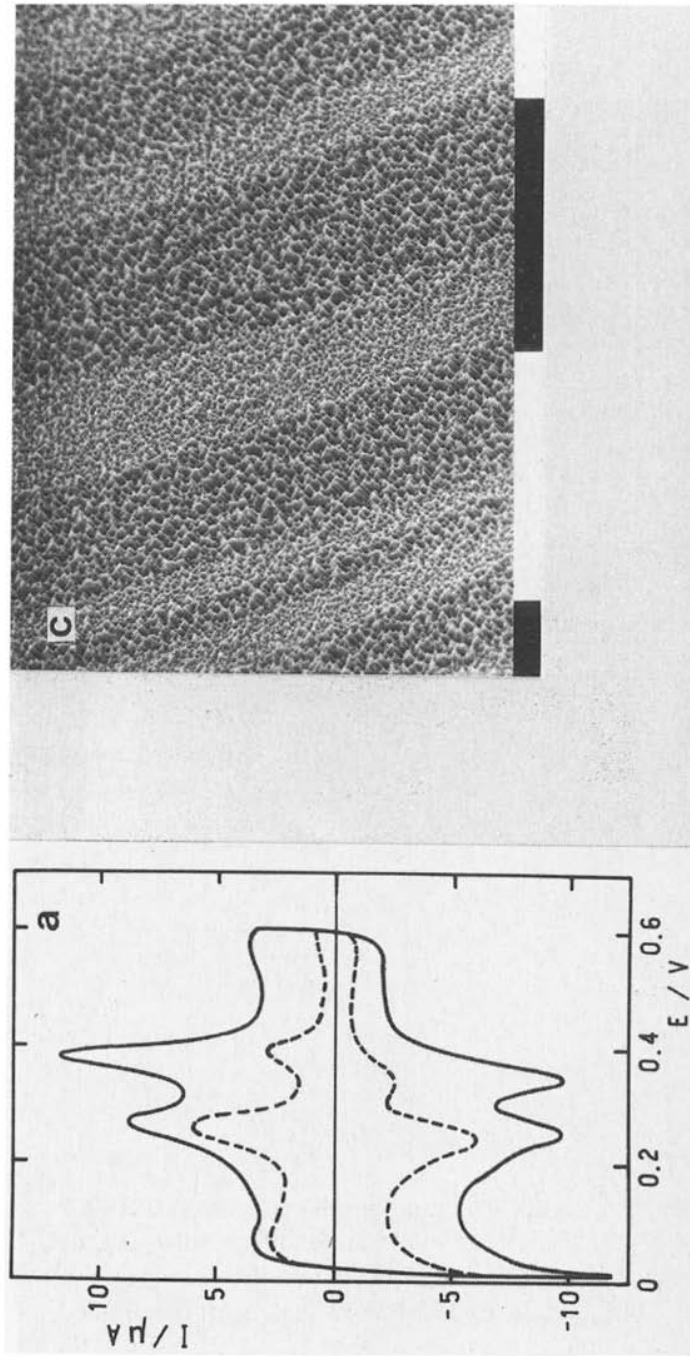
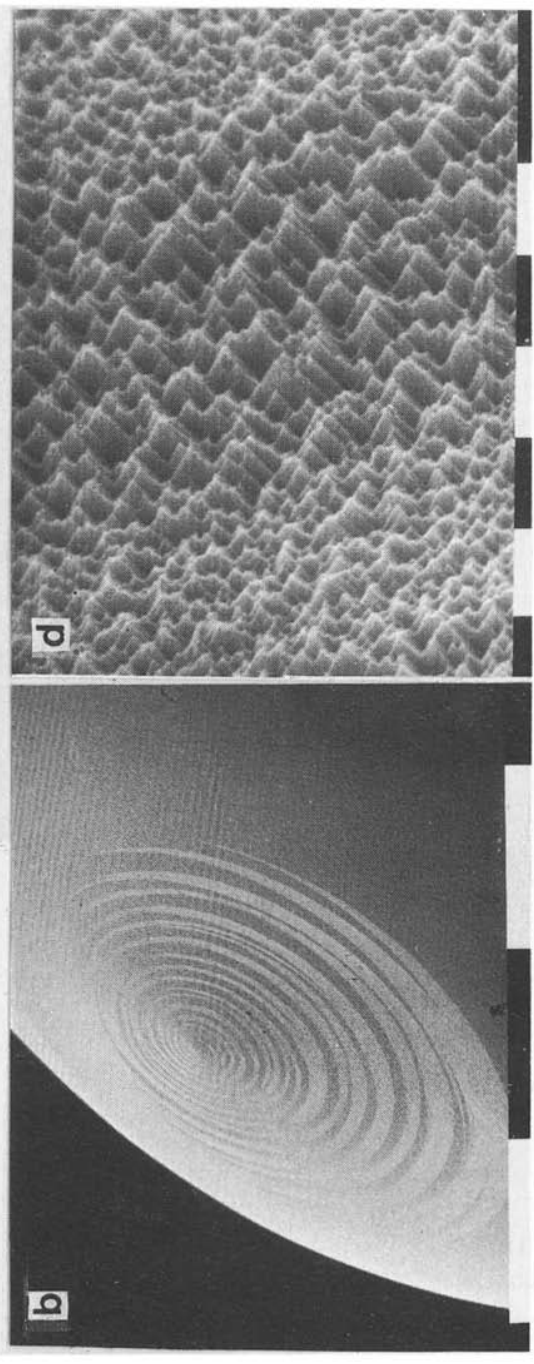

过

동

:

45

$>$.

D

章

滘

30

N

$\Rightarrow$

넌

荡

政

E

a

然

善

츨

용

递

留

돌

to

:

空

क

递

i)

in 9



7

.

돌

E

$\rightarrow$ 焉

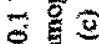

플

3 은

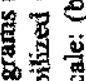

和窎

要

के

त

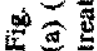


in the range 0.3 to $-0.1 \mathrm{~V}$, in order to produce an electroreduced $\mathrm{Pt}$ overlayer. The voltammogram of the resulting Pt overlayer was obtained as indicated for type I experiments. These data were also complemented with SEM micrographs.

Comparison of the voltammogram resulting after the RSWP treatment with the reference voltammogram allows us to estimate both the development of a certain degree of pco, and the relative change in the electrode roughness $(R)$, as follows. The degree of pco was evaluated in terms of the height ratio of the voltammetric electrodesorption peaks related to weakly $\left(h_{1}\right)$ and strongly $\left(h_{2}\right)$ bound H-adatoms. For the reference (untreated) $\mathrm{Pt}$ surface, the $h_{2} / h_{1}$ ratio was 0.58 . On the other hand, the value of $R$ was determined as the charge ratio, $R=Q_{\mathrm{T}}^{\mathrm{H}} / Q_{\mathrm{R}}^{\mathrm{H}}$, where $Q_{\mathrm{T}}^{\mathrm{H}}$ and $Q_{\mathrm{R}}^{\mathrm{H}}$ refer to the $\mathrm{H}$-adatom electrosorption charges resulting for the treated electrode $(T)$ and the reference one (R), respectively.

\section{RESULTS}

\section{Type I experiments}

These runs were made by applying RSWP treatments with $f=0.62 \mathrm{kHz}, E_{1}=0$ $\mathrm{V}, 1.6 \mathrm{~V} \leqslant E_{\mathrm{u}} \leqslant 2.35 \mathrm{~V}$ and $t=10 \mathrm{~min}$. For $E_{u}<1.7 \mathrm{~V}$, no appreciable changes in the voltammogram of the treated sample as compared to the blank can be observed. The blank voltammogram (Fig. 1a) in the $\mathrm{H}$-adatom potential range exhibits two pairs of approximately reversible adsorption/desorption peaks, $h_{1}^{\mathrm{a}} / h_{1}^{\mathrm{c}}$ and $h_{2}^{\mathrm{a}} / h_{2}^{\mathrm{c}}$, with a separation in the peak potentials of about $0.12 \mathrm{~V}$. However, remarkable changes can be seen in the voltammogram of the treated Pt surface at $E_{\mathrm{u}}=1.9 \mathrm{~V}$ (Fig. 1a) as both $R$ and $h_{2} / h_{1}$ increase. Accordingly, after the electrochemical treatment the value of $R$ becomes 1.5 and the contribution of the strongly bound $\mathrm{H}$-adatom reactions is now enhanced considerably $\left(h_{2} / h_{1}=1.4\right)$. Furthermore, Fig. $1 \mathrm{~b}$ shows that only a few cycles at $0.1 \mathrm{~V} / \mathrm{s}$ are necessary to attain complete electroreduction of the O-containing surface species formed at $E_{\mathrm{u}}=1.9 \mathrm{~V}$. The SEM micrograph of the resulting $\mathrm{Pt}$ overlayer (Fig. lc) exhibits a rather regular spike-like structure growing in a preferred direction. The best definition for the spike-like type of structure emerges for $E_{\mathrm{u}}=2.0 \mathrm{~V}$ and $E_{\mathrm{u}}=2.1 \mathrm{~V}$. In this case, the electrochemical facetting for $E_{\mathrm{u}}=2.0 \mathrm{~V}$ becomes surprisingly clear and homogeneous domains appear, distributed concentrically around one of the crystallographic poles of the spherical microelectrode (Figs. $2 \mathrm{~b}-\mathrm{d}$ ). The corresponding voltammogram of the resulting surface shows an increase in both $R$ and the $h_{2} / h_{1}$ ratio ( $R=2.4, h_{2} / h_{1}=1.6$ ) (Fig. 2a). Otherwise, for $E_{\mathrm{u}}=2.1 \mathrm{~V}$ various domains with different morphologies can be observed over the entire microsphere, all the domains exhibiting a definite pco (Figs. 3b-d). Furthermore, the voltammogram of the treated surface (Fig. 3a) shows again a considerable increase in $R(R=2.1)$, whereas the $h_{2} / h_{1}$ ratio attains the maximum value $\left(h_{2} / h_{1}=1.7\right)$ (Fig. 4$)$. The situation changes rather drastically, however, when $E_{\mathrm{u}}>2.1 \mathrm{~V}$. Then, the Pt overlayers present relatively large values for the $h_{2} / h_{1}$ ratio and a dramatic increase in $R$ (Fig. 4). For $E_{\mathrm{u}}=2.3 \mathrm{~V}$, the surface of the Pt overlayer is now made up of small sticking spherical globular structures (Fig. 5b), and the corresponding voltam- 

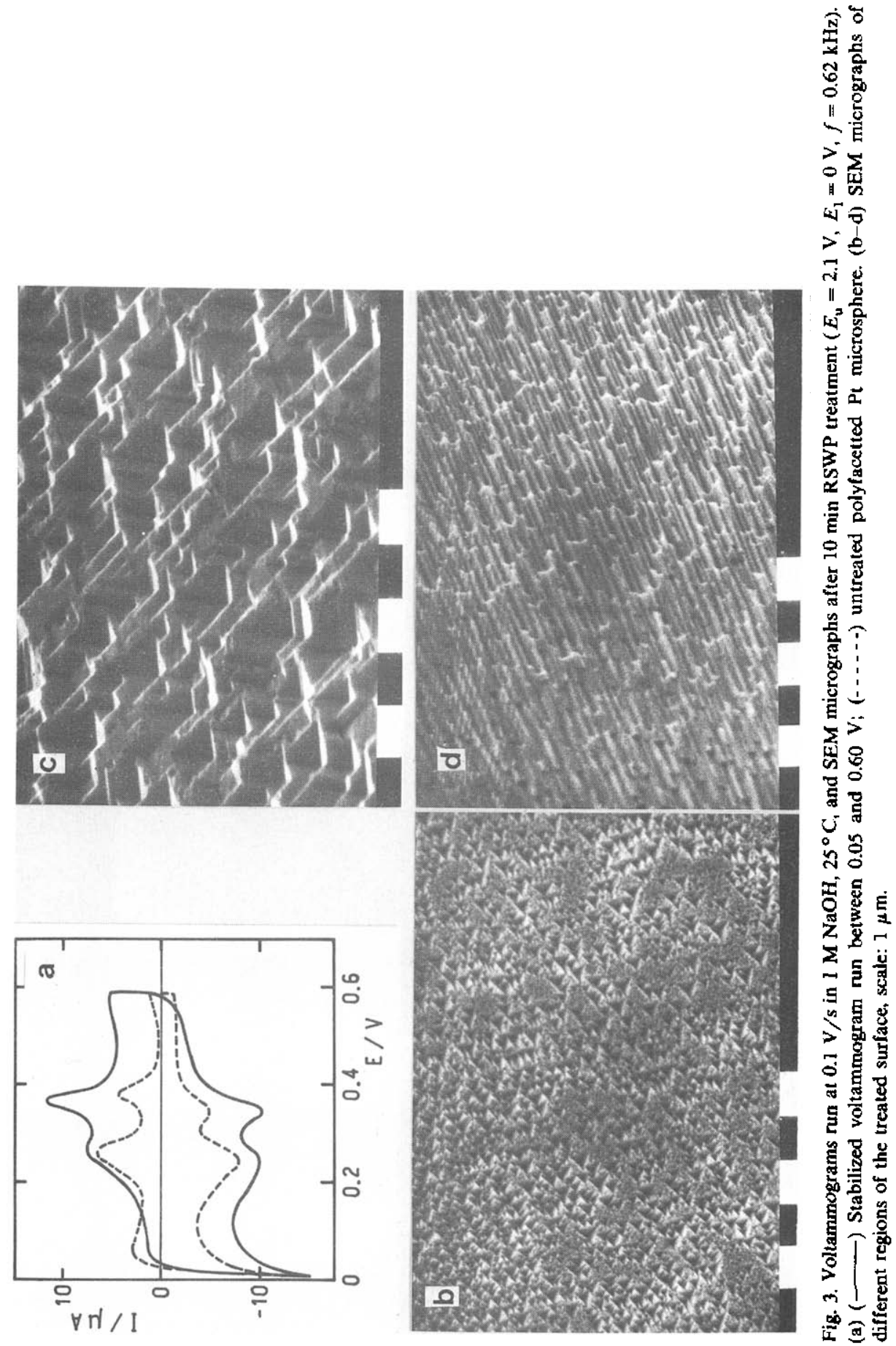


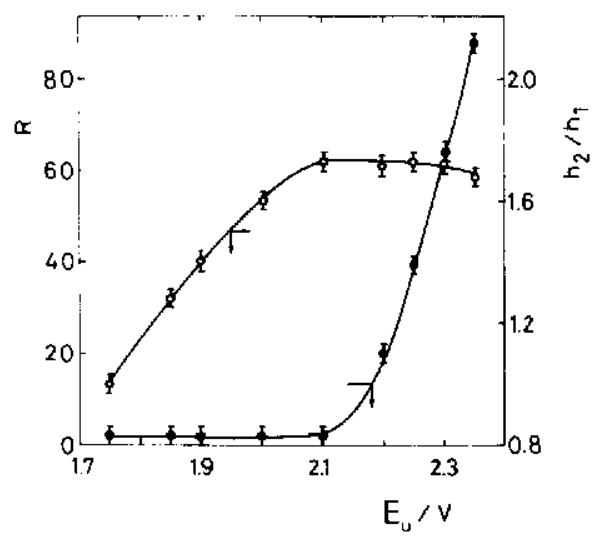

Fig. 4. Dependence of $R$ and $h_{2} / h_{1}$ on $E_{\mathrm{u}}$ derived from stabilized voltammograms run at $0.1 \mathrm{~V} / \mathrm{s}$ between 0.05 and $0.60 \mathrm{~V}$ in $1 \mathrm{M} \mathrm{NaOH}, 25^{\circ} \mathrm{C}$, after $10 \min R S W P$ treatment $\left(E_{1}=0 \mathrm{~V}, f=0.62 \mathrm{kHz}\right.$ ).

mogram shows a notable increase in $R(R=65)$ and a large value of the $h_{2} / h_{1}$ ratio $\left(h_{2} / h_{1}=1.7\right.$ ) (Fig. 5a). It is interesting to observe that in this case the resulting metal surface becomes very active for both molecular hydrogen evolution and electrooxidation as large cathodic and anodic currents appear at potentials lower than $0.2 \mathrm{~V}$. This type of globular structure is much better defined for $E_{\mathrm{u}}>2.3 \mathrm{~V}$ (Fig. 6e) and, in this case, the increase in $R$ becomes more significant than that of

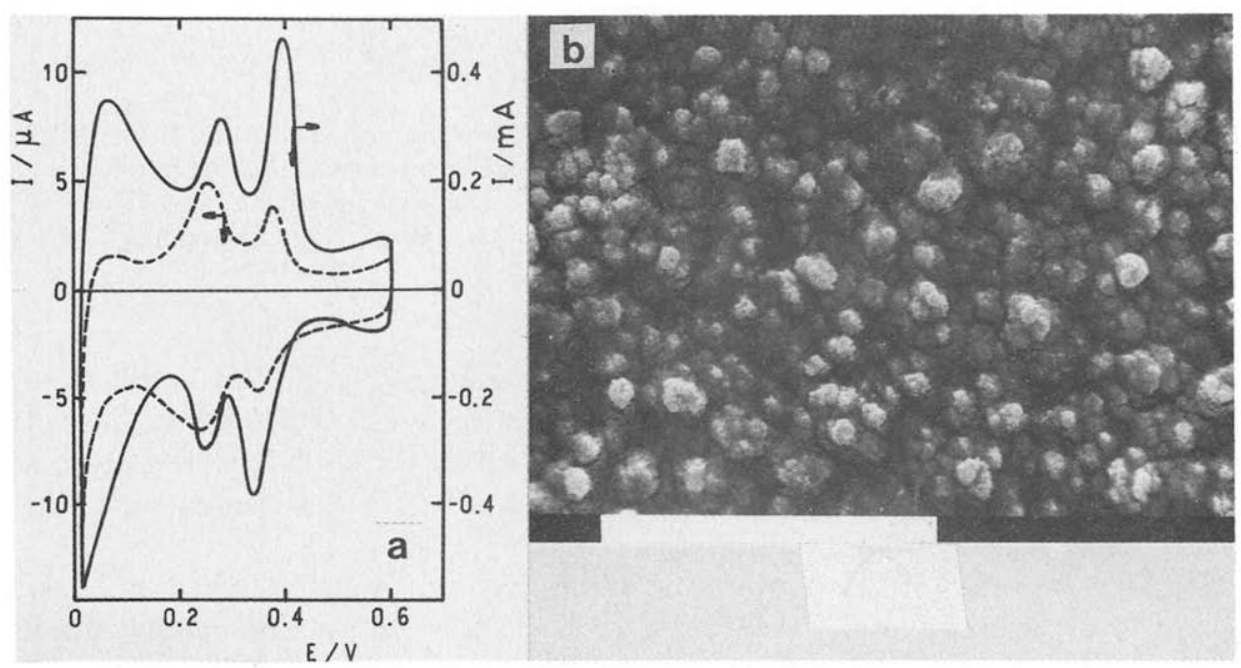

Fig. 5. Voltammograms run at $0.1 \mathrm{~V} / \mathrm{s}$ in $1 \mathrm{M} \mathrm{NaOH}, 25^{\circ} \mathrm{C}$, and SEM micrographs after $10 \mathrm{~min}$ RSWP treatment ( $E_{\mathrm{a}}=2.3 \mathrm{~V}, E_{1}=0 \mathrm{~V}, f=0.62 \mathrm{kHz}$ ). (a) (—) Stabilized voltammogram run between 0.05 and $0.60 \mathrm{~V} ;(-\ldots$.$) . - untreated polyfacetted Pt microsphere. (b) SEM micrograph of the treated surface,$ scale: $10 \mu \mathrm{m}$. 


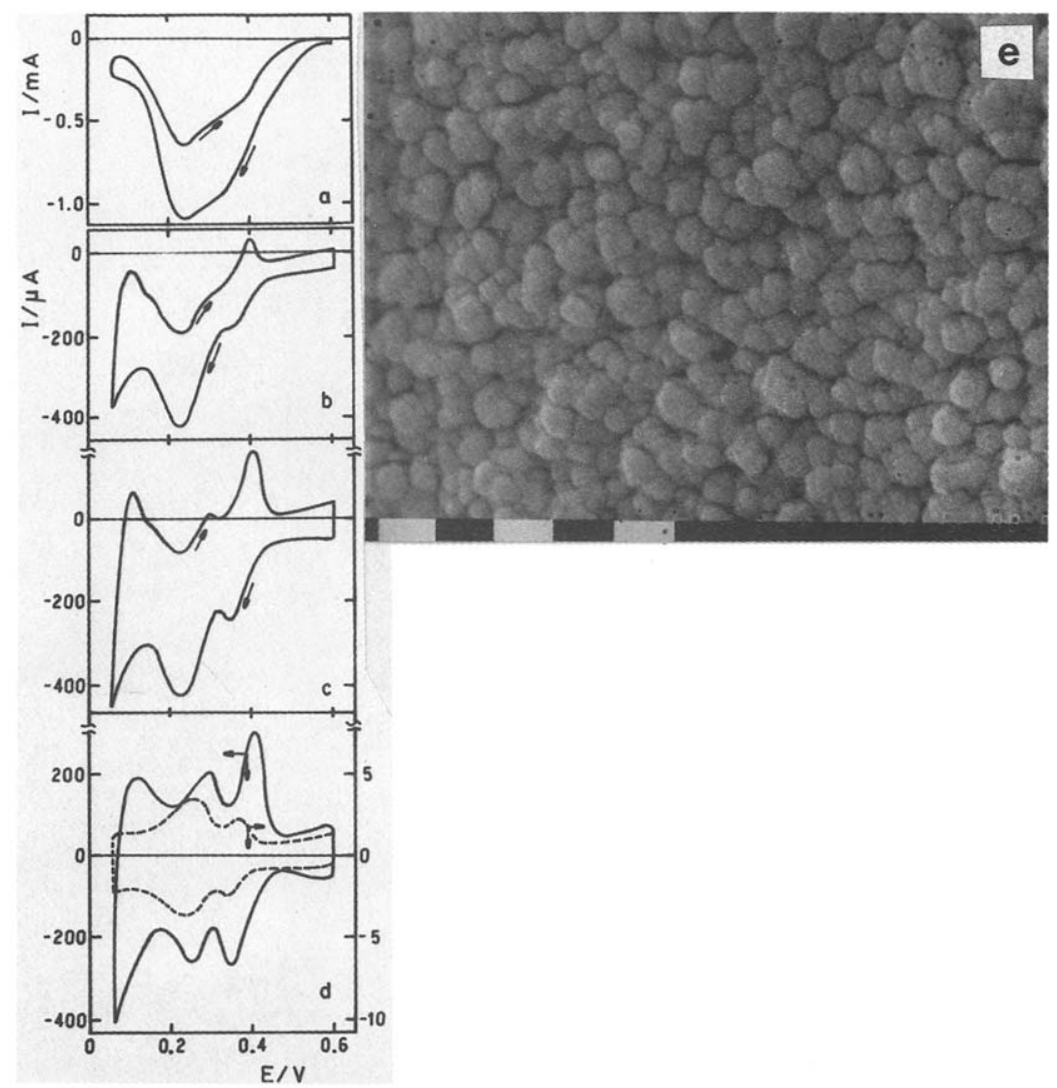

Fig. 6. Voltammograms run at $0.1 \mathrm{~V} / \mathrm{s}$ in $1 \mathrm{M} \mathrm{NaOH}, 25^{\circ} \mathrm{C}$, and SEM micrographs after $10 \mathrm{~min}$ RSWP treatment $\left(E_{\mathrm{u}}-2.35 \mathrm{~V}, E_{1}=0 \mathrm{~V}, f=0.62 \mathrm{kHz}\right)$. (a-d) Transition from the first negative potential scan to the stabilized voltammogram: (a) 1st cycle; (b) 5Sth cycle; (c) 110th cycle; (d) (- $\longrightarrow$ ) 330th cycle, stabilized voltammogram; (- - - - -) untreated polyfacetted Pt microsphere. (e) SEM micrograph of the treated surface, scale: $1 \mu \mathrm{m}$.

the $h_{2} / h_{1}$ ratio, the latter remaining practically constant (Fig. 4). Furthermore, for $E_{\mathrm{u}}=2.35 \mathrm{~V}$, potential cycling at $0.1 \mathrm{~V} / \mathrm{s}$ between 0.05 and $0.6 \mathrm{~V}$ shows that the complete voltammetric electroreduction of the relatively thick oxide layer formed at $E_{\mathrm{u}}$ can be achieved only after a relatively prolonged potential cycling time (Fig. 6a-d).

The characteristics of the $\mathrm{Pt}$ overlayer resulting from the electroreduction of this type of oxide layer are largely dependent upon the selected electroreduction conditions, as was the case for similar experiments already reported for $\mathrm{Pt}$ in acid solutions $[7,8,14]$. The experimental data described further provide additional information about the influence of the electroreduction conditions on the characteristics of the Pt overlayer. 


\section{Type II experiments}

The electroreduction, at $E_{\mathrm{r}}=0.3 \mathrm{~V}$, of hydrous $\mathrm{Pt}$ oxide layers accumulated under the following conditions: $E_{\mathrm{u}}=2.3 \mathrm{~V}, E_{1}=0 \mathrm{~V}, f=0.62 \mathrm{kHz}, t=3 \mathrm{~min}$, furnishes Pt overlayers which show a clear globular structure distributed nearly uniformly over the entire microsphere (Fig. 7b), the corresponding value of $R$ being about 134 (Fig. 7a). Furthermore, the voltammogram of the treated surface also shows an increase of the contribution of the weakly bound $\mathrm{H}$-adatom reactions as compared to the blank. Although the globular structure is maintained for other values of $E_{\mathrm{r}}$ (Fig. 7d), the value of $R$ decreases as $E_{\mathrm{r}}$ is set progressively more negative, $R$ reaching a value of about 30 when $E_{\mathrm{r}}=-0.1 \mathrm{~V}$ (Fig. 7c). Likewise, as $E_{\mathrm{r}}$ is set stepwise more negative, the sponge-like structure becomes progressively
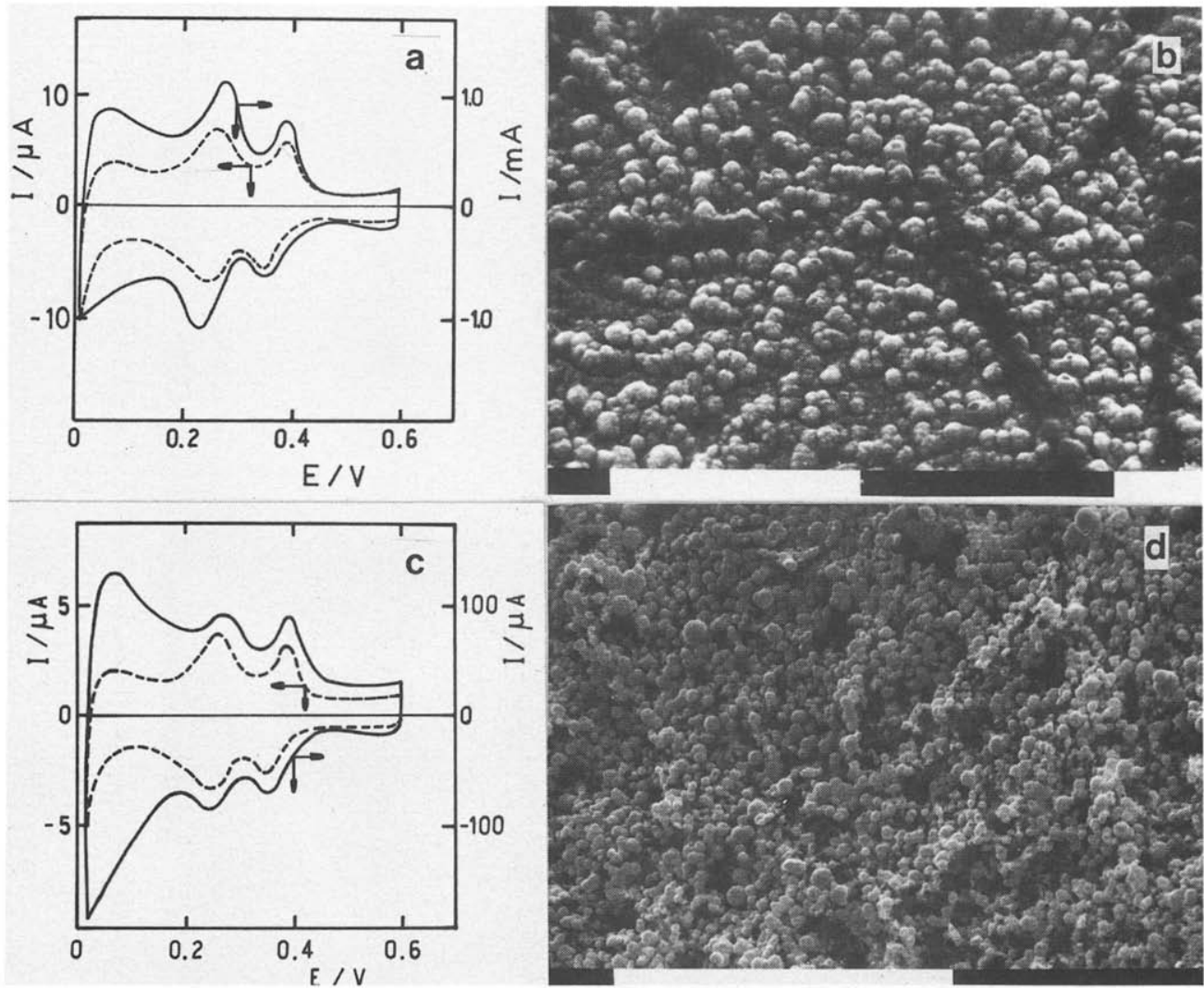

Fig. 7. Voltammograms run at $0.1 \mathrm{v} / \mathrm{s}$ in $1 \mathrm{M} \mathrm{NaOH}, 25^{\circ} \mathrm{C}$, and SEM micrographs after $3 \mathrm{~min}$ RSWP treatment $\left(E_{\mathrm{u}}=2.3 \mathrm{~V}, E_{1}=0 \mathrm{~V}, f=0.62 \mathrm{kHz}\right)$ followed by potentiostatic electroreduction at $E_{\mathrm{r}}=0.3 \mathrm{~V}$ (a,b) and $E_{\mathrm{r}}=-0.1 \mathrm{~V}(\mathrm{c}, \mathrm{d}) .(\mathrm{a}, \mathrm{c})(-)$ Stabilized voltammograms run between $0.05 \mathrm{~V}$ and $0.6 \mathrm{~V}$; (- - - -) untreated polyfacetted Pt microsphere. (b,d) SFM micrographs of the treated surfaces, scale: 10 $\mu \mathrm{m}$. 


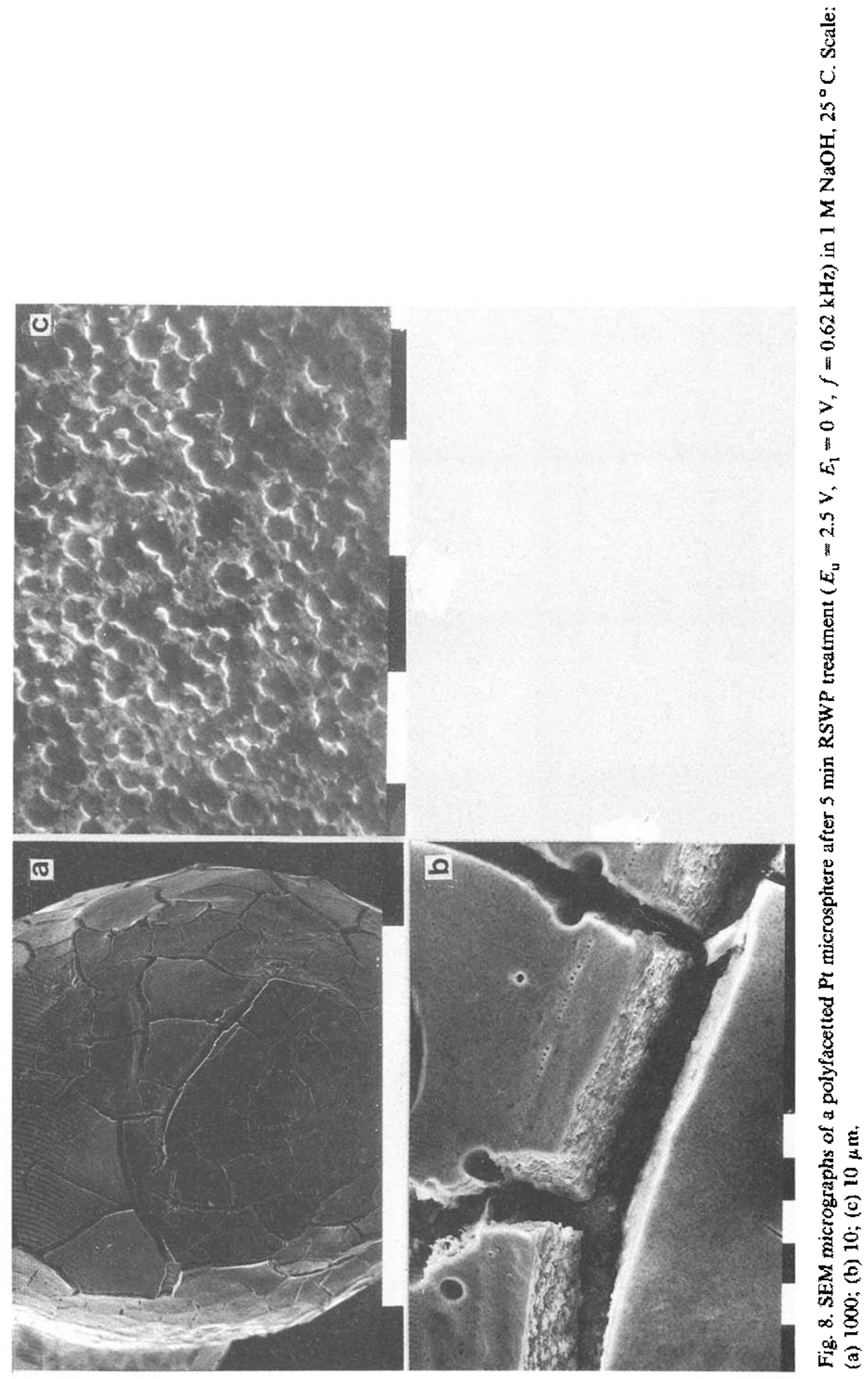




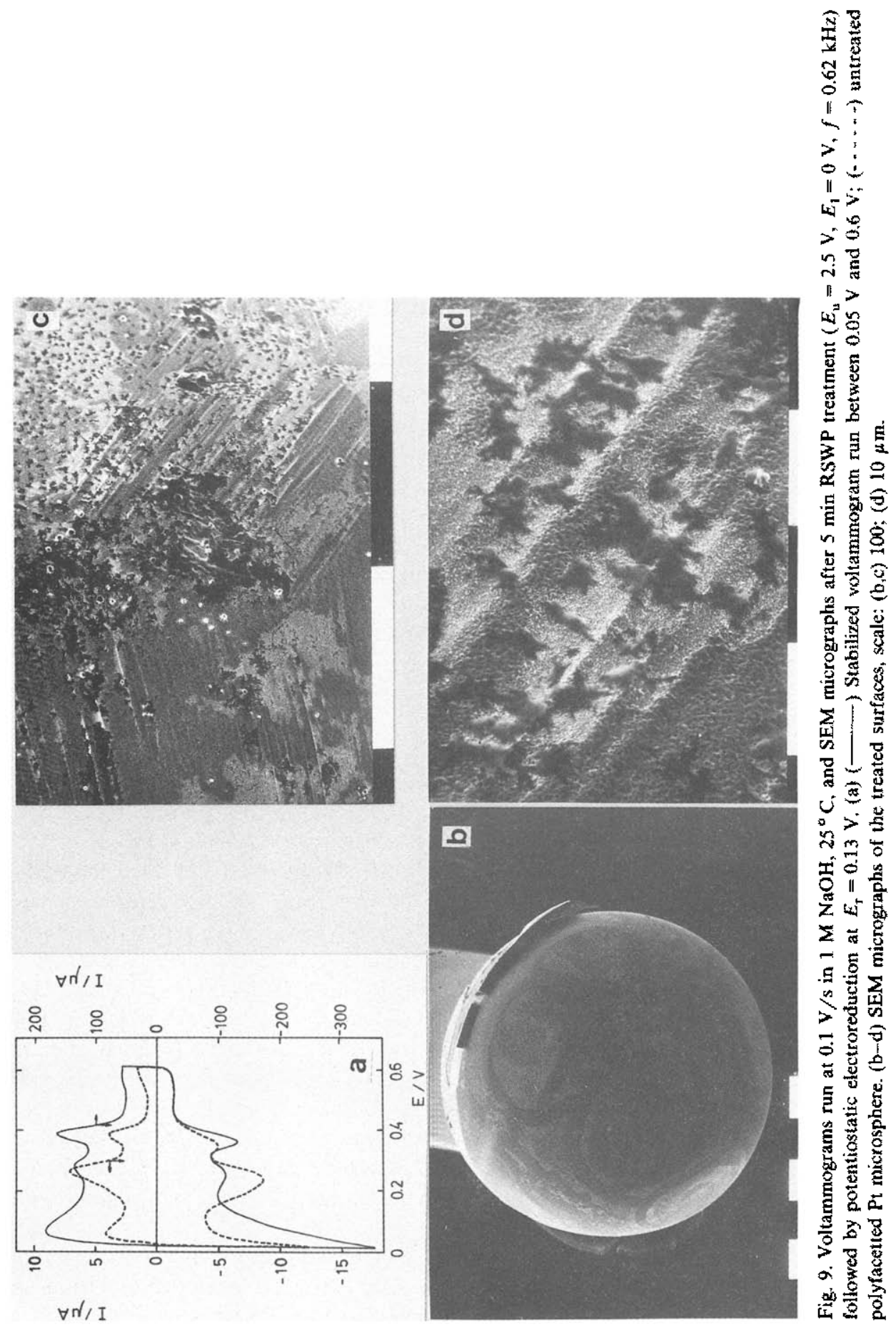


more compact, a fact which correlates with the trend in the decrease of the corresponding values of $R$ as derived from the voltammograms. Furthermore, the voltammograms of the electroreduced Pt overlayers show an increase of the $h_{2} / h_{1}$ ratio as $E_{\mathrm{r}}$ becomes more negative, i.e., $h_{2} / h_{1}=0.6$ at $E_{\mathrm{r}}=0.3 \mathrm{~V}$, and $h_{2} / h_{1}=0.95$ at $E_{\mathrm{r}}=-0.1 \mathrm{~V}$.

Runs were also made under conditions where a very thick Pt oxide layer is formed by applying a RSWP treatment between $E_{\mathrm{u}}=2.5 \mathrm{~V}$ and $E_{1}=0 \mathrm{~V}$ at $f=0.62 \mathrm{kHz}$ for $t=5 \mathrm{~min}$. The SEM micrographs of this oxide layer before electroreduction show cracks, presumably produced by the vacuum treatment of the specimens (Fig. 8a). In principle, the $\mathrm{Pt}$ oxide layer appears as a rather homogeneous layer except for the occurrence of a small number of cylindrical pits of about $5 \mu \mathrm{m}$ diameter which are probably associated with centres which are either preferentially attacked or particularly active for oxygen evolution during the positive balf-cycle of the periodic potential treatment (Fig. 8b). The thickness of this layer, as seen in Fig. 8b, is about $10 \mu \mathrm{m}$, and except for its outer skin, no discontinuities can be seen in the bulk of the oxide layer. At larger magnifications the electrode surface shows a globular structure (Fig. 8c). When the thick oxide layer formed under the above conditions is electroreduced at $E_{\mathrm{r}}=0.13 \mathrm{~V}$, the SEM micrographs of the resulting Pt overlayer show certain well defined geometric domains on the Pt microsphere (Fig. 9b-d). The corresponding voltammogram of the electroreduced Pt overlayer (Fig. 9a) shows a remarkable increase in both $R(R=25)$ and the $h_{2} / h_{1}$ ratio, $\left(h_{2} / h_{1}=1.4\right)$.

\section{DISCUSSION}

The electrochemical facetting and roughening of $\mathrm{Pt}$ in base solutions require firstly the accumulation of an oxide layer through the application of a RSWP treatment, at a certain frequency within a potential range which is defined by an upper, $E_{u}$, and a lower, $E_{1}$, potential limit, and subsequently, the electroreduction of the anodic layer under controlled potential conditions. The formation of relatively thick oxide layers after the RSWP treatment justifies, as a first exploratory approach, taking the equilibrium potentials calculated from thermodynamic data of bulk compounds as reference values, despite the fact that either the oxide layer formation, or its electroreduction, or both processes take place under non-equilibrium conditions (Table 1). The useful values of $E_{\mathrm{u}}$ are more positive than the equilibrium potentials of the redox couples involving $\mathrm{Pt}$ oxides and hydroxides $[15,16]$. It should be noted that in this case the useful values of $E_{\mathrm{u}}$ are considerably greater than those required in acid solutions, but the values of $E_{1}$ as well as the RSWP frequency are not appreciably different from those already established in acids $[7,9]$. Nevertheless, in the former case the optimal frequency is slightly lower than in the latter.

The fact that the useful values of $E_{\mathrm{u}}$ are positive with respect to those assembled in Table 1, can be taken as a first indication that the electrochemical facetting and roughening of $\mathrm{Pt}$ in alkaline solutions implies predominantly the participation of 
TABLE 1

Standard electrode potentials (vs. RHE) of different $\mathrm{Pt} / \mathrm{Pt}$ oxide redox couples at $25^{\circ} \mathrm{C}$

\begin{tabular}{lll}
\hline Reaction & $E^{\circ} / \mathrm{V}$ & Reference \\
\hline (1) $\mathrm{PtOH}+\mathrm{H}^{+}+\mathrm{e}^{-}=\mathrm{Pt}+\mathrm{H}_{2} \mathrm{O}$ & 0.85 & 15 \\
(2) $\mathrm{PtO}+2 \mathrm{H}^{+}+2 \mathrm{e}^{-}=\mathrm{Pt}+\mathrm{H}_{2} \mathrm{O}$ & 0.98 & 16 \\
(3) $\mathrm{PtO}_{2}+2 \mathrm{H}^{+}+2 \mathrm{e}^{-}=\mathrm{PtO}+\mathrm{H}_{2} \mathrm{O}$ & 1.045 & 16 \\
(4) $\mathrm{PtO}_{2}+4 \mathrm{H}^{+}+2 \mathrm{e}^{-}=\mathrm{Pt}^{2+}+2 \mathrm{H}_{2} \mathrm{O}$ & 0.84 & 16 \\
\hline
\end{tabular}

oxide electroformation/electroreduction processes rather than metal electrodissolution/metal electrodeposition, as was the case for acid solutions [9]. Therefore, the periodic perturbing potential should promote the formation of a hydrous $\mathrm{Pt}$ oxide layer through the initial $\mathrm{Pt} / \mathrm{OH}^{-}$ion interaction in alkaline solutions. One should expect that the resulting anodic layer contains an excess of $\mathrm{OH}^{-}$ions which, besides stabilizing the hydrous structure of the oxide layer, favours its growth through the soluble $\mathrm{Pt}^{2+}$ species produced during the electroreduction half-cycle, according to reaction (4) (Table 1), particularly when the value of $E_{\mathrm{u}}$ is sufficiently positive to make possible the formation of $\mathrm{Pt}(\mathrm{IV})$ species. The presence of an excess of $\mathrm{OH}^{-}$ trapped within the hydrous Pt oxide matrix grown in alkaline solutions is consistent with the presence of $\mathrm{Na}^{+}$[17]. The type of oxide which is accumulated during the electrochemical treatment can be electroreduced completely during the successive potential cycling at low potential sweep rate covering the $\mathrm{H}$-adatom potential range, as can be seen, for instance, from the sequence of voltammograms shown in Figs. 1b and $6 \mathrm{a}-\mathrm{d}$.

Let us first consider the possible structure of the hydrous oxide $\mathrm{Pt}$ layers. According to results reported in the literature $[18,19]$ the structure of the hydrous $\mathrm{Pt}$ oxide layer accumulated during the fast perturbing potential treatment in aqueous solutions can be described in terms of at least two different types of oxide layer. The first layer, in contact with the metal surface, is usually a compact monolayer $[17,20]$, with a composition ranging from $\mathrm{PtOH}$ to $\mathrm{PtO} \cdot \mathrm{H}_{2} \mathrm{O}$ or $(\mathrm{O}) \mathrm{Pt}(\mathrm{OH})_{2}$, depending on the preparation conditions. The second layer, which can grow to produce a thick film, is considered as a hydrous, low diffraction index [21], low density material $[19,22]$ which has been formulated as $\left[\mathrm{PtO}_{2}(\mathrm{OH})_{2}\left(\mathrm{H}_{2} \mathrm{O}\right)_{2}\right]^{2-}$ or $\left.\left[\mathrm{Pt}(\mathrm{OH})_{6}\right)\right]^{2-}[18,19]$, although there is evidence that, in turn, this thick hydrous $\mathrm{Pt}$ oxide layer involves two distinguishable components, as can be seen from its potentiostatic electroreduction [8]. This is in agreement with a previous observation derived from the electroreduction of thick acid-grown Pt oxide layers, indicating a probably heterogeneous structure for these layers [23]. X-ray photoelectron spectroscopy revealed that $\mathrm{Pt}(\mathrm{IV})$ species are present in the thick oxide layer structure formed at high potentials [24-26]. Earlier investigations of the growth of the second oxide layer in acid media [27] have shown that the optimal $E_{\mathrm{u}}$ value for it is about $2.3 \mathrm{~V}$ (RHE). In this case the corresponding optimal potential window ranges from 2.1 to $2.5 \mathrm{~V}$. It has also been demonstrated clearly that the hydrous $\mathrm{Pt}$ oxide layer grown in alkaline 
solutions does not differ significantly in structure and composition from the acid-grown deposit [18,19]. The composition of the thick oxide layer has been described as essentially the anion of platinic acid, $\mathrm{H}_{2} \mathrm{Pt}(\mathrm{OH})_{6}[19]$, since this acid and its salts have been characterized in the bulk state by $\mathrm{X}$-ray techniques [28]. In the case of thick oxide layers formed in alkaline solutions, the first layer is electroreduced voltammetrically at $0.6 \mathrm{~V}[18,19]$, whereas the thicker layer, which appears under low $f$ and high $E_{\mathrm{u}}$ limits as a yellow film, is not reduced above $0 \mathrm{~V}$ (RHE) during the negative sweep, although part of the material existing beneath the yellow hydrous film is presumably electroreduced at $0.25 \mathrm{~V} \mathrm{[19].} \mathrm{This} \mathrm{result} \mathrm{is} \mathrm{to}$ some extent opposite to that found in the present work, where the electroreduction process gives no erratic currents in the $\mathrm{H}$-atom adsorption region.

On the other hand, taking into account that XPS analysis of thick and thin oxide layers formed on Pt electrodes in sulphuric acid are characterized as $\mathrm{Pt}(\mathrm{OH})_{4}$ as the main species [29-31] in addition to the fact that XPS data even below about $2.4 \mathrm{~V}$ also show the existence of an oxide layer which contains $\mathrm{Pt}$ in a lower formal oxidation state $[24,25,32,33]$, one can conclude that the RSWP in the optimal frequency and potential window ranges operates according to the following reactions.

Let us first consider the reactions occurring during the anodic half cycles of the RSWP, which can be described as follows:

$$
\begin{aligned}
& \mathrm{Pt}+\mathrm{OH}^{-}=\mathrm{Pt}(\mathrm{OH})+\mathrm{e}^{-} \\
& \mathrm{Pt}(\mathrm{OH})+x \mathrm{OH}^{-}+y \mathrm{H}_{2} \mathrm{O} \\
& \quad=\mathrm{Pt}(\mathrm{OH})_{2} \cdot z \mathrm{H}_{2} \mathrm{O}+(x-1) \mathrm{OH}^{-}+(y-z) \mathrm{H}_{2} \mathrm{O}+\mathrm{e}^{-} \\
& \mathrm{Pt}(\mathrm{OH})_{2} \cdot z \mathrm{H}_{2} \mathrm{O}+(x-1) \mathrm{OH}^{-}+(y-z) \mathrm{H}_{2} \mathrm{O} \\
& \quad=\mathrm{Pt}(\mathrm{OH})_{4} \cdot(z-2) \mathrm{H}_{2} \mathrm{O}+(x-3) \mathrm{OH}^{-}+(y-z+2) \mathrm{H}_{2} \mathrm{O}+2 \mathrm{e}^{-}
\end{aligned}
$$

Reaction (1) implies the formation of a $\mathrm{Pt}(\mathrm{OH})$ monolayer in alkaline solution. Reaction (2) corresponds to the second oxidation stage of $\mathbf{P t}$, yielding a hydrous $\mathbf{P t}$ oxide layer containing a concentration of trapped $\mathrm{OH}^{-}$and $\mathrm{Na}^{+}$ions lower than that of the bulk, in agreement with XPS data [17]. Reaction (3) refers to the third oxidation level of $\mathrm{Pt}$, producing a hydrous $\mathrm{Pt}$ oxide layer as in reaction (2), except for the higher oxidation state of Pt. When the potential is held at a high positive potential for a prolonged time, the $\mathrm{Pt}(\mathrm{IV})$ species can lose water and produce $\mathrm{PtO}_{2}+4 \mathrm{H}_{2} \mathrm{O}$ according to:

$$
\begin{aligned}
& \mathrm{Pt}(\mathrm{OH})_{4} \cdot(z-2) \mathrm{H}_{2} \mathrm{O} \rightarrow \mathrm{PtO}_{2} \cdot 4 \mathrm{H}_{2} \mathrm{O}+(z-4) \mathrm{H}_{2} \mathrm{O} \\
& \mathrm{PtO}_{2} \cdot 4 \mathrm{H}_{2} \mathrm{O} \rightarrow \mathrm{PtO}_{2} \cdot(4-p) \mathrm{H}_{2} \mathrm{O}+p \mathrm{H}_{2} \mathrm{O}
\end{aligned}
$$

Reactions (4) and (5) account for the yellowish oxide layer observed under slow electrochemical perturbation conditions. The rate of a reaction such as (5) is expected to be rather slow, as it involves nucleation-and-growth mechanisms as found for $\mathrm{Cu}$ and $\mathrm{Ag}$ oxide layers and salts [34]. Therefore, whether the hydrous $\mathrm{Pt}$ oxide layer is formed by one, two or three different types of layers should depend 
on the potential perturbation conditions employed in the preparation, which would provide different time windows for the occurrence of each reaction depending on the corresponding rate constants. The reaction sequence (1) to (5) implies a change in the Pt oxide to water ratio in the composition of the anodic layer which is consistent with recent ellipsometric data [21].

On the other hand, the reactions occurring during the negative half-cycles of the RSWP can be interpreted as follows:

$$
\begin{aligned}
& \mathrm{Pt}(\mathrm{OH})_{4} \cdot(z-2) \mathrm{H}_{2} \mathrm{O}+(x-3) \mathrm{OH}^{-}+(y-z+2) \mathrm{H}_{2} \mathrm{O}+2 \mathrm{e}^{-} \\
& \quad=\mathrm{Pt}^{2+}\left(\mathrm{H}_{2} \mathrm{O}\right)_{6}+(x+1) \mathrm{OH}^{-}+(y-6) \mathrm{H}_{2} \mathrm{O} \\
& \quad=\mathrm{Pt}(\mathrm{OH})_{2} \cdot z \mathrm{H}_{2} \mathrm{O}+(x-1) \mathrm{OH}^{-}+(y-z) \mathrm{H}_{2} \mathrm{O} \\
& \mathrm{Pt}(\mathrm{OH})_{2} \cdot z \mathrm{H}_{2} \mathrm{O}+2 \mathrm{e}^{-}=\mathrm{Pt}^{0}+2 \mathrm{OH}^{-}+z \mathrm{H}_{2} \mathrm{O}
\end{aligned}
$$

Reaction (6) should predominate at high values of $f$ and should contribute to the accumulation of the oxide layer and to an increase of the amount of Pt(II) species in the oxide layer. This reaction shows that the formation of $\mathrm{Pt}(\mathrm{OH})_{2}$ goes through a soluble $\mathrm{Pt}^{2+}$ species. The latter has been detected through rotating ring-disk electrode experiments [35]. Otherwise, reactions (6) and (7) contribute simultaneously when the complete electroreduction of the anodic layer takes place at potentials higher than $0 \mathrm{~V}$.

Although in the present case the presence of the hexahydroxy platinic acid anion is not completely discarded, the structure and composition suggested for the hydrous Pt oxide layer formed under electrochemical treatment seems to be more adequate for correlation to the surface analysis data.

The formation of the electroreduced $\mathrm{Pt}$ overlayer in alkaline solutions, as in the case of acid solutions, implies a phase change which assists the transfer of $\mathrm{Pt}^{2+}$ ions from the oxide layer to the metal surface and its location at the lattice. Whether this process takes place at a constant volume or at the maximum volume change, a rough or a smooth $\mathrm{Pt}$ overlayer can be produced [36]. It is also observed that as reaction (7) takes place in the $\mathrm{H}$-atom electroadsorption potential range, the (100) type pco should be favoured as the presence of $\mathrm{H}$-adatoms on the surface impedes the development of the highest density crystalline arrangements.

\section{ACKNOWLEDGEMENTS}

This work was supported by the Universidad Nacional de La Plata, the Consejo Nacional de Investigaciones Científicas y Técnicas, the Comision de Investigaciones Científicas (Provincia de Buenos Aires), and the Regional Program for the Scientific and Technological Development of the Organization of American States.

\section{REFERENCES}

1 J.P. Hoare, Electrochim. Acta, 5 (1964) 599.

2 S. Gilman, J. Electroanal. Chem., 9 (1965) 276.

3 T. Biegler, J. Electrochem. Soc., 116 (1965) 1138. 
4 J.C. Canullo, W.E. Triaca and A.J. Arvia, J. Electroanal. Chem., 175 (1984) 377.

5 R. Cerviño, W.E. Triaca and A.J. Arvia, J. Electrochem. Soc., 132 (1985) 266.

6 A.J. Arvia, J.C. Canullo, E. Custidiano, C.L. Perdriel and W.E. Triaca, Electrochim. Acta, 31 (1986) 1359 .

7 A. Visintin, J.C. Canullo, W.E. Triaca and A.J. Arvia, J. Electroanal. Chem., 239 (1988) 67.

8 A.E. Bolzán, A.M. Castro Luna, A. Visintin, R.C. Salvarezza and A.J. Arvia, J. Electrochim. Acta, 33 (1988) 1743 .

9 A. Visintin, J.C. Canullo, W.E. Triaca and A.J. Arvia, J. Electroanal. Chem., 267 (1989) 191.

10 R. Cerviño, W.E. Triaca and A.I. Arvia, J. Electroanal. Chem., 182 (1985) 51.

11 J.P. Hoare in P. Delahay (Ed), Advances in Electrochemistry and Electrochemical Engineering, Vol. 6, Wiley, New York, 1967, p. 201.

12 J.C. Canullo, W.E. Triaca and A.J. Arvia, J. Electroanal. Chem., 200 (1986) 397.

13 W.E. Triaca, T. Kessler, J.C. Canullo and A.J. Arvia, J. Electrochem. Soc., 134 (1987) 1165.

14 A.C. Chialvo, W.E. Triaca and A.J. Arvia, J. Electroanal. Chem., 146 (1983) 93.

15 C.L. Perdriel, W.E. Triaca and A.J. Arvia, J. Electroanal. Chem., 205 (1986) 279.

16 A.J. Bard, R. Parsons and J. Jordan (Eds.), Standard Potentials in Aqueous Solutions, Marcel Dekker, New York, 1985 , p. 353.

17 M. Peuckert, Electrochim. Acta, 29 (1984) 1315.

18 L.D. Burke and M.E.G. Lyons in R.E. White, J.O'M. Bockris and B.E. Conway (Eds.), Modern Aspects of Electrochemistry, Vol, 18, Plenum Press, New York, 1986, p. 169.

19 L.D. Burke, M.B.C. Roche and W.A. O'Leary, J. Appl. Electrochem., 18 (1988) 781.

20 B.E. Conway and A. Angerstein-Kozlowska, Acc. Chem. Res., 14 (1981) 49.

21 C.L. Perdriel, J. Zerbino and A.J. Arvia, Electrochim. Acta, submitted.

22 L.D. Burke and M.B.C. Roche, J. Electroanal. Chem., 164 (1984) 315.

23 S.D. James, J. Electrochem. Soc., 116 (1969) 1681.

24 G.C. Allen, P.M. Tucker, A. Capon and R. Parsons, Electrochim. Acta, 50 (1974) 335.

25 J.S. Hammond and N. Winograd, J. Electroanal, Chem., 78 (1977) 55.

26 M. Peuckert, F.P. Coenen and H.P. Bonzel, Electrochim. Acta, 29 (1984) 1305.

27 J. Balej and O. Spalek, Collect. Czech. Chem. Commun., 37 (1972) 499.

28 H.G. Scott, Acta Crystallogr. B, 35 (1979) 3014.

29 M. Peuckert and H. Ibach, Surf. Sci., 136 (1984) 319.

30 M. Peuckert and H.P. Bonzel, Surf. Sci., 145 (1984) 239.

31 E. Rach and J. Heitbaum, Electrochim. Acta, 31 (1986) 477.

32 K.S. Kim, N. Winograd and R.E. Davis, J. Am. Chem. Soc., 93 (1971) 6296.

33 T. Dickinson, A.F. Povey and P.M.A. Sherwood, J. Chem. Soc. Faraday Trans. 1, 71 (1975) 298.

34 R. Salvarezza, J. Gómez Recerra and A.J. Arvia, Electrochim. Acta, 613 (1988) 1431.

35 D.F. Untereker and S. Bruckenstein, J. Electrochem. Soc., 121 (1974) 360.

36 A.J. Arvia, R.C. Salvarezza and W.E. Triaca, Electrochim. Acta, 34 (1989) 1057. 